\title{
Oxygen Evolution Activity and Chemical Stability of Ni and Fe Based Perovskites in
} Alkaline Media

\author{
Adolphsen, Jens Q.; Sudireddy, Bhaskar R.; Gil, Vanesa ; Chatzichristodoulou, Christodoulos
}

Published in:

Journal of The Electrochemical Society

Link to article, DOI:

10.1149/2.0911810jes

Publication date:

2018

Document Version

Peer reviewed version

Link back to DTU Orbit

Citation (APA):

Adolphsen, J. Q., Sudireddy, B. R., Gil, V., \& Chatzichristodoulou, C. (2018). Oxygen Evolution Activity and Chemical Stability of Ni and Fe Based Perovskites in Alkaline Media. Journal of The Electrochemical Society, 165(10), F827-F835. https://doi.org/10.1149/2.0911810jes

\section{General rights}

Copyright and moral rights for the publications made accessible in the public portal are retained by the authors and/or other copyright owners and it is a condition of accessing publications that users recognise and abide by the legal requirements associated with these rights.

- Users may download and print one copy of any publication from the public portal for the purpose of private study or research.

- You may not further distribute the material or use it for any profit-making activity or commercial gain

- You may freely distribute the URL identifying the publication in the public portal 


\title{
Oxygen Evolution Activity and Chemical Stability of Ni and Fe Based Perovskites in Alkaline Media
}

\author{
Jens Q Adolphsen, ${ }^{1, z}$ Bhaskar R. Sudireddy, ${ }^{1}$ Vanesa Gil, ${ }^{2,3}$ \\ and Christodoulos Chatzichristodoulou ${ }^{1}$
}

\author{
${ }^{I}$ Department of Energy Conversion and Storage, Technical University of Denmark, 4000 Roskilde, Denmark \\ ${ }^{2}$ Aragon Hydrogen Foundation, 22197 Huesca, Spain \\ ${ }^{3}$ Fundación Agencia Aragonesa para la Investigación y Desarrollo (ARAID), Zaragoza, Spain
}

\begin{abstract}
The electrochemical activity of $\mathrm{LaNiO}_{3}, \mathrm{La}_{0.97} \mathrm{NiO}_{3}, \mathrm{LaNi}_{0.6} \mathrm{Fe}_{0.4} \mathrm{O}_{3}, \mathrm{La}_{0.97} \mathrm{Ni}_{0.6} \mathrm{Fe}_{0.4} \mathrm{O}_{3}$ and $\mathrm{La}_{2} \mathrm{Ni}_{0.9} \mathrm{Fe}_{0.1} \mathrm{O}_{4}$, toward the oxygen evolution reaction (OER) was measured in $1 \mathrm{M} \mathrm{KOH}$ at room temperature. All materials showed comparable OER activity with Tafel slopes in the range $56-98 \mathrm{mV} / \mathrm{dec}$. The overvoltage at $10 \mathrm{~mA} \cdot \mathrm{cm}^{-2}$, measured on a well-defined geometric surface area, was in the range $0.38-0.45 \mathrm{~V}$. The best performing materials among the ones investigated were $\mathrm{LaNiO}_{3}$ (multiphase) and $\mathrm{La}_{2} \mathrm{Ni}_{0.9} \mathrm{Fe}_{0.1} \mathrm{O}_{4}$. The chemical stability of the stoichiometric materials was also assessed in $31 \mathrm{wt} \%$ and $45 \mathrm{wt} \% \mathrm{KOH}$ respectively at $100^{\circ} \mathrm{C}$ and $220^{\circ} \mathrm{C}$. All materials were partially decomposed after 1 week of exposure at $220^{\circ} \mathrm{C}$. After 1 week of exposure at $100^{\circ} \mathrm{C} \mathrm{LaNiO}_{3}$ had formed secondary phases whereas $\mathrm{LaNi}_{0.6} \mathrm{Fe}_{0.4} \mathrm{O}_{3}$ and $\mathrm{La}_{2} \mathrm{Ni}_{0.9} \mathrm{Fe}_{0.1} \mathrm{O}_{4}$ showed only traces of secondary phase. The main secondary phases were in all cases $\mathrm{La}(\mathrm{OH})_{3}, \mathrm{NiO}, \mathrm{Ni}(\mathrm{OH})_{2}$ and $\mathrm{Fe}_{2} \mathrm{O}_{3}$. These observations indicate that the investigated oxygen electrode materials are not suitable for operation in alkaline electrolysis cells above $100^{\circ} \mathrm{C}$. (C) 2018 The Electrochemical Society. [DOI: 10.1149/2.0911810jes]
\end{abstract}

Manuscript submitted April 13, 2018; revised manuscript received June 7, 2018. Published July 21, 2018.

The electrolysis of water in alkaline electrolysis cells (AECs) has been used commercially for around 100 years but it has remained a niche technology for hydrogen production, far surpassed by steam reforming due to lower production prices. ${ }^{1}$ With the increased focus on renewable energy though, alkaline electrolysis is experiencing a renewed interest. At its current level of technological maturity alkaline electrolysis suffers from a low power density $\left(\sim 0.3-0.9 \mathrm{~W} \cdot \mathrm{cm}^{-2}\right)$ and only a moderate efficiency (60-80\% based on higher heating value) compared to proton exchange membrane electrolysis cells (PEMECs) and solid oxide electrolysis cells (SOECs). ${ }^{2}$ The main advantages of AECs are their long lifetime and the fact that none of the electrodes require the use noble metals.

Improving the power density and the cell efficiency is therefore needed for the technology to become more competitive relative to other hydrogen production technologies. It is possible to increase the power density and efficiency without the use of noble metals. Raising the operating temperature is an effective way to enhance performance. Typically, AECs are operated at approximately $80^{\circ} \mathrm{C}$. Recent results, using a new cell design, allowing the temperature to be increased up to at least $250^{\circ} \mathrm{C}$ upon pressurized operation, show a sharp increase in power density (by a factor of 10) and improved cell efficiency ${ }^{3-5}$ compared to conventional AECs. However, increasing the operating temperature poses a challenge for the chemical stability of the electrode materials. Conventionally used oxygen electrode materials, such as nickel, are not an option because of their break-away oxidation at the operating conditions. Hence, the chemical stability of the oxygen electrode poses a significant challenge. Certain classes of (complex) oxides hold the potential to offer much better stability compared to the conventional metals used, as they are already oxidized, while also being able to provide adequate electrocatalytic activity.

The main challenge is therefore to identify suitable materials, which besides having good electrocatalytic activity toward the oxygen evolution reaction (OER) also exhibit adequate chemical stability at high temperature and pressure (HTP) conditions. Perovskite oxides, with the structural formula $\mathrm{ABO}_{3}$, are of interest as OER electrocatalysts and many of them are also electronically conductive, allowing them to be used as both electrocatalyst and current collector. The Asite contains a large cation, e.g. La, $\mathrm{Sr}$ or $\mathrm{Ba}$, compared to the B-site, which is typically a transition metal, e.g., Ti, Mn or Ni. Several perovskites and related structures containing $\mathrm{Ni}$ and $\mathrm{Co}$ as the transition metal have been shown to possess good electrocatalytic activity toward the OER.$^{6-9}$ It is, however, still questionable whether they can provide adequate performance over time at operating conditions. The double

${ }^{\text {z} E-m a i l: ~ j e n q u i @ d t u . d k ~}$ perovskite $\mathrm{Pr}_{\mathrm{x}} \mathrm{Ba}_{1-\mathrm{x}} \mathrm{CoO}_{3}(\mathrm{PBCO})^{8-11}$ has been suggested as both an active and stable electrocatalyst at standard conditions with comparable electrocatalytic activity to the state-of-the-art materials $\mathrm{IrO}_{2}$ and $\mathrm{RuO}_{2}{ }^{12-14} \mathrm{~A}$ study, utilizing cyclic voltammetry to determine stability of $\mathrm{PCBO}$ at $80^{\circ} \mathrm{C}$ in $1 \mathrm{M} \mathrm{KOH}$, showed that the performance of a $100 \mathrm{~nm}$ layer drops after less than 12 hours. This was correlated to surface leaching of $\mathrm{Pr}$ and $\mathrm{Ba}$ and hence a change in surface composition and structure. The above exemplifies that the stability of electrocatalysts at standard conditions provide insufficient information about their stability at operating conditions. Therefore, electrocatalyst characterization requires improved protocols for assessing the performance over time under realistic operating conditions.

Having a mix of $\mathrm{Ni}$ and $\mathrm{Fe}$ in the structure has been shown to improve the electrochemical activity toward the OER of $\mathrm{Ni} / \mathrm{Fe}$ metal oxyhydroxides ${ }^{15,16}$ and perovskites. ${ }^{17}$ In the following study, we show the results of the electrochemical activity of various La-Ni-Fe-oxides toward the OER. Four perovskite type materials were tested with the following nominal compositions: $\mathrm{LaNiO}_{3}(\mathrm{LN})$, $\mathrm{La}_{0.97} \mathrm{NiO}_{3}$ (L97N), $\mathrm{LaNi}_{0.6} \mathrm{Fe}_{0.4} \mathrm{O}_{3}$ (LNF) and $\mathrm{La}_{0.97} \mathrm{Ni}_{0.6} \mathrm{Fe}_{0.4} \mathrm{O}_{3}$ (L97NF) and one Ruddlesden-Popper phase: $\mathrm{La}_{2} \mathrm{Ni}_{0.9} \mathrm{Fe}_{0.1} \mathrm{O}_{4}$ (LNF$\mathrm{RP}$ ). In addition, the chemical stability of these materials, under high temperature conditions in concentrated $\mathrm{KOH}$, was investigated.

\section{Experimental}

Characterization of powders.-All the powders are $99.9 \%$ purity and synthesized with the combustion spray pyrolysis method by Praxair Surface Technologies (Praxair Technology, USA). The phase analysis of the powders was carried out using X-ray diffraction (XRD, Bruker Advance D8, operated with a $\mathrm{Cu} \mathrm{K} \alpha$ source). The powder's specific surface areas (SSAs) were determined by the BrunauerEmmett-Teller (BET) method (Autosorb 1-MP, Quantachrome Instruments, USA) using $\mathrm{N}_{2}$ gas. The powders were degassed for $3 \mathrm{~h}$ at $300^{\circ} \mathrm{C}$ prior to the measurements. The density of the powder was determined using gas pycnometry (AccuPyc 1330, Micromeritics, USA). Cylindrical pellets were fabricated by uniaxially pressing the powders to pellets followed by isostatic pressing at $280 \mathrm{MPa}$ for $30 \mathrm{~s}$. These pellets were used for sintering dilatometry (DIL 402C, Netzsch, Germany) measurements in the temperature range room temperature (RT) $-1400^{\circ} \mathrm{C}$ in air with a heating rate of $5^{\circ} \mathrm{C} / \mathrm{min}$ and holding time at $1400^{\circ} \mathrm{C}$ of $5 \mathrm{~h}$. In addition, the thermal stability during sintering of the $\mathrm{LaNiO}_{3}$ powder was determined by thermogravimetric analysisdifferential thermal analysis (TGA-DTA, STA 409 C, Netzsch, Germany). The samples were heated in air $/ \mathrm{O}_{2}$ to $1100 / 1250^{\circ} \mathrm{C}$ with heating rates $10^{\circ} \mathrm{C} / \mathrm{min}$ from $\mathrm{RT}-700^{\circ} \mathrm{C} / 850^{\circ} \mathrm{C}$ followed by $5^{\circ} \mathrm{C} / \mathrm{min}$ from $750-1100^{\circ} \mathrm{C} / 850-1250^{\circ} \mathrm{C}$. The flow rate of the air $/ \mathrm{O}_{2}$ was $50 \mathrm{ml} / \mathrm{min}$. 
Preparation of samples for electrochemical measurements.The samples used for the electrochemical activity measurements were pressed and sintered bars of as-received powder. Bars were pressed using the same procedure as described above and subsequently, they were sintered at $1400^{\circ} \mathrm{C}$ for $24 \mathrm{~h}$ in air to achieve geometric densities $>92 \%$ and densities based on the Archimedes method $>96 \%$. The bars used for electrochemical testing were further cut, grinded and polished (StruersTegrapol-32, Denmark) in successive steps to similar dimensions $(17-18 \mathrm{~mm} \times 5-6 \mathrm{~mm} \times 0.9-1.5 \mathrm{~mm})$. The final polishing was carried out with a $1 \mu \mathrm{m}$ diamond dispersion (Nap B1 Diapro, Struers, Denmark) using a MD-Nap polishing pad (Struers, Denmark). The phase analysis of the sintered and polished samples was carried out using XRD. The root-mean-square roughness of the polished pellets was measured with a Cyberscan Vantage Profilometer (Cyber Technologies, Germany).

The root mean square roughness is given as:

$$
R_{R M S}=\sqrt{\frac{1}{n} \sum_{i}^{n} y_{i}^{2}}
$$

where $y_{i}$, is the vertical deviation of a point on the surface from the mean surface height and $n$ is the number of points included in the calculation. The scanned area was $\min .10 \mathrm{~mm}^{2}$ with a $10 \mu \mathrm{m}$ step size, corresponding to minimum of 100,000 points. Any systematic sloping of the pellet surface was compensated for in the ScanCT 7.5 software accompanying the equipment.

Electrochemical measurements.-The electrochemical activity measurements were performed using a three electrode setup. All measurements took place in a polytetrafluoroethylene (PTFE) holder, which was positioned in a closed, not airtight, container with $\mathrm{N}_{2}$ flowing into it. The electrochemical characterization employed a ca. $1 \mathrm{M}$ $\mathrm{KOH}$ solution (ACS reagent., $>85 \% \mathrm{KOH}$ basis, Fluka) prepared with Milipore water $(18 \mathrm{M} \Omega \cdot \mathrm{cm})$. $\mathrm{KOH}$ is hygroscopic. Besides the ACS reagent contains $\leq 2.0 \% \mathrm{~K}_{2} \mathrm{CO}_{3}, \leq 0.053 \%$ cation and heavy metal traces, $\leq 0.013 \%$ anion traces and $\leq 0.021 \%$ other impurities. The measured $\mathrm{pH}$ of the ca. $1 \mathrm{M}$ solution was 14.0. A Gamry Reference 3000 potentiostat (Gamry Instruments, USA) was used. The polished bar was the working electrode with an Au current collector pressed against its back side. A Pt mesh with a Pt wire attached to it was used as the counter electrode and a relative hydrogen electrode (Hydroflex, Gaskatel, Germany) as the reference electrode. A Zirfon separator was used to separate the working electrode from the reference and counter electrode. The current densities were normalized according to the exposed geometrical surface area of the bar being tested. The electrochemical data collected consists of chronopotentiostatic $(\mathrm{CP})$ measurements performed at $0.5,1,2,5,10,25$ and $50 \mathrm{~mA} \cdot \mathrm{cm}^{-2}$ with 30 min duration at each current density. Each CP measurement was followed by an amperostatic electrochemical impedance spectroscopy (EIS) measurement to determine the ohmic contribution $\left(R_{s}\right)$. All results presented have been corrected for the serial resistance $\left(i \cdot R_{s}\right)$ contribution. The amperostatic EIS measurements were used to determine the electrochemically active surface area (ECSA) from the ratio of the double layer capacitance of the tested surface relative to an ideal smooth oxide surface.

The surface of the polished bars before and after the electrochemical measurements was investigated with a field emission scanning electron microscope (FE-SEM) from Zeiss (Merlin Zeiss, Germany) equipped with a Schottky field emitter gun.

Chemical stability measurements.-The chemical stability of the materials was assessed by exposing the as-received (in case of LNF, a pre-calcined version is also included for the reasons explained in $\mathrm{Re}$ sults and discussion section) powders to $45 \mathrm{wt} \% \mathrm{KOH}$ inside a polytetrafluoroethylene (PTFE) lined autoclave. No electrical potential was applied during these tests. The autoclave was heated in a furnace at $220^{\circ} \mathrm{C}$ for a week. No external pressure was applied to the autoclave, so the internal buildup pressure was approx. 15 bar, corresponding to the vapor pressure of the $\mathrm{KOH}$ solution at $220^{\circ} \mathrm{C}$. Afterwards the
$\mathrm{KOH}$ solution was extracted and the residual powder was rinsed in milipore water until a neutral $\mathrm{pH}$ of the water was reached. The rinsed powder was dried by heating with $1{ }^{\circ} \mathrm{C} / \mathrm{min}$ to $500^{\circ} \mathrm{C}$ and back to room temperature prior to phase analysis by XRD. Chemical stability analysis was also conducted after exposing the powders in $31 \mathrm{wt} \%$ $\mathrm{KOH}$ at $100^{\circ} \mathrm{C}$ and in $30 \mathrm{wt} \% \mathrm{KOH}$ at RT for a week. Similar chemical stability measurements, as mentioned, above were conducted with powder pressed into pellets and sintered at $1100^{\circ} \mathrm{C}$ for $1 \mathrm{~h}$.

\section{Results and Discussion}

Phase analysis.-The XRD patterns of LN, L97, LNF, L97NF and LNF-RP powders are shown and indexed in Figure 1. LN and L97N are indexed with PDF 33-0711, LNF and L97NF are indexed with PDF-88-0637 and LNF-RP is indexed with the XRD spectrum from Ref. 18 together with PDF 86-1668. The powders are phase pure according to XRD, except the L97N powder, which contains traces of NiO (PDF-44-1159), illustrated in Figure 1, and the LNF powder which contains traces of $\mathrm{Ni}(\mathrm{OH})_{3}$ (PDF 36-1481). The LNF powder is phase pure after calcination at $800^{\circ} \mathrm{C}$ and hence the calcined LNF powder's XRD pattern is referred to in Figure 1. For these reasons pre-calcined LNF powder is also included in the chemical stability studies.

The XRD patterns of the densely sintered and polished LN, L97N pellets diverge a lot from the as-received powders because the perovskite phase is partially decomposed during sintering. During the partial decomposition, a loss of $\mathrm{O}_{2}$ occurs while Ruddlesden Popper phases $\left(\mathrm{La}_{n+1} \mathrm{Ni}_{\mathrm{n}} \mathrm{O}_{3 \mathrm{n}+1}, \mathrm{n}=1,2\right.$ and 3$)$ are formed in successive steps along with NiO. ${ }^{19-21}$ The TG curves shown in Figure 2, exhibit the onset for partial decomposition at $1000^{\circ} \mathrm{C}$ in air and $1070^{\circ} \mathrm{C}$ in $\mathrm{O}_{2}$ which is in agreement with previous work. ${ }^{21,22}$ The weight loss is caused by $\mathrm{O}_{2}$ escaping the material. The initial decline of the TG curves up to approx. $300^{\circ} \mathrm{C}$ can be ascribed to water evaporation and the continued decline of the $\mathrm{TG}$ curves between $300^{\circ} \mathrm{C}$ and the decomposition onset temperature is ascribed to $\mathrm{O}_{2}$ being expelled from the LN structure due to the reduction of $\mathrm{Ni}^{3+}$ to $\mathrm{Ni}^{2+}$. Overall the $\mathrm{LN}$ powder is seen to drop weight faster when heated in air compared to in $\mathrm{O}_{2}$; suggesting that the thermal stability of the perovskite phase is lower when heated in air compared to in $\mathrm{O}_{2-}$.

The sintered and polished LNF bars contain no secondary phases whereas the L97NF bars contain traces of $\mathrm{NiO}$ and the LNF-RP bars contain traces of unidentified phase(s). The electrochemically tested bars show no deviation in their XRD patterns from those of the sintered and polished bars.

Powder size and sintering characteristics.-The as-received powders differ in terms of particle size and SSA, as shown in Figure 3. The as-received LNF powder exhibit significantly larger SSA $\left(25.1 \mathrm{~m}^{2} \cdot \mathrm{g}^{-1}\right)$ than the other powders. After calcination at $800^{\circ} \mathrm{C}$ the $\mathrm{SSA}$ is reduced to $8.0 \mathrm{~m}^{2} \cdot \mathrm{g}^{-1}$ and hence comparable to the order powders. The LNF powder has the smallest particle sizes followed by LN, L97N and L97NF, which have similar sizes. The LNF-RP particle size is significantly larger than the other powders.

The sintering profiles in Figure 4 of the powders in pressed pellet form show similar sintering characteristics though the LN and L97N exhibit two stages of sintering. Initially, the sintering of LN and L97N starts around $1000^{\circ} \mathrm{C}$, followed by a plateau and finally a maximum sintering rate in the interval $1300-1350^{\circ} \mathrm{C}$. The plateau is assumed to be associated with the decomposition of the perovskite phase (cf. Figure 2). The LNF and L97NF reach the maximum sintering rate around $1200^{\circ} \mathrm{C}$. The decrease in the elongation rate of LNF from around $200^{\circ} \mathrm{C}$ is associated with the combustion of remains from the synthesis process. This is supported by the XRD patterns (not shown), which showed traces of $\mathrm{La}(\mathrm{OH})_{3}$. Additionally, density measurements show that there is an increase in powder density from 6.1 to 6.9 $\mathrm{g} \cdot \mathrm{cm}^{-3}$ before vs after calcination. This is pointing toward the fact that the synthesis process was stopped prematurely, resulting also in a larger SSA. The theoretical density of the rhombohedral LNF 

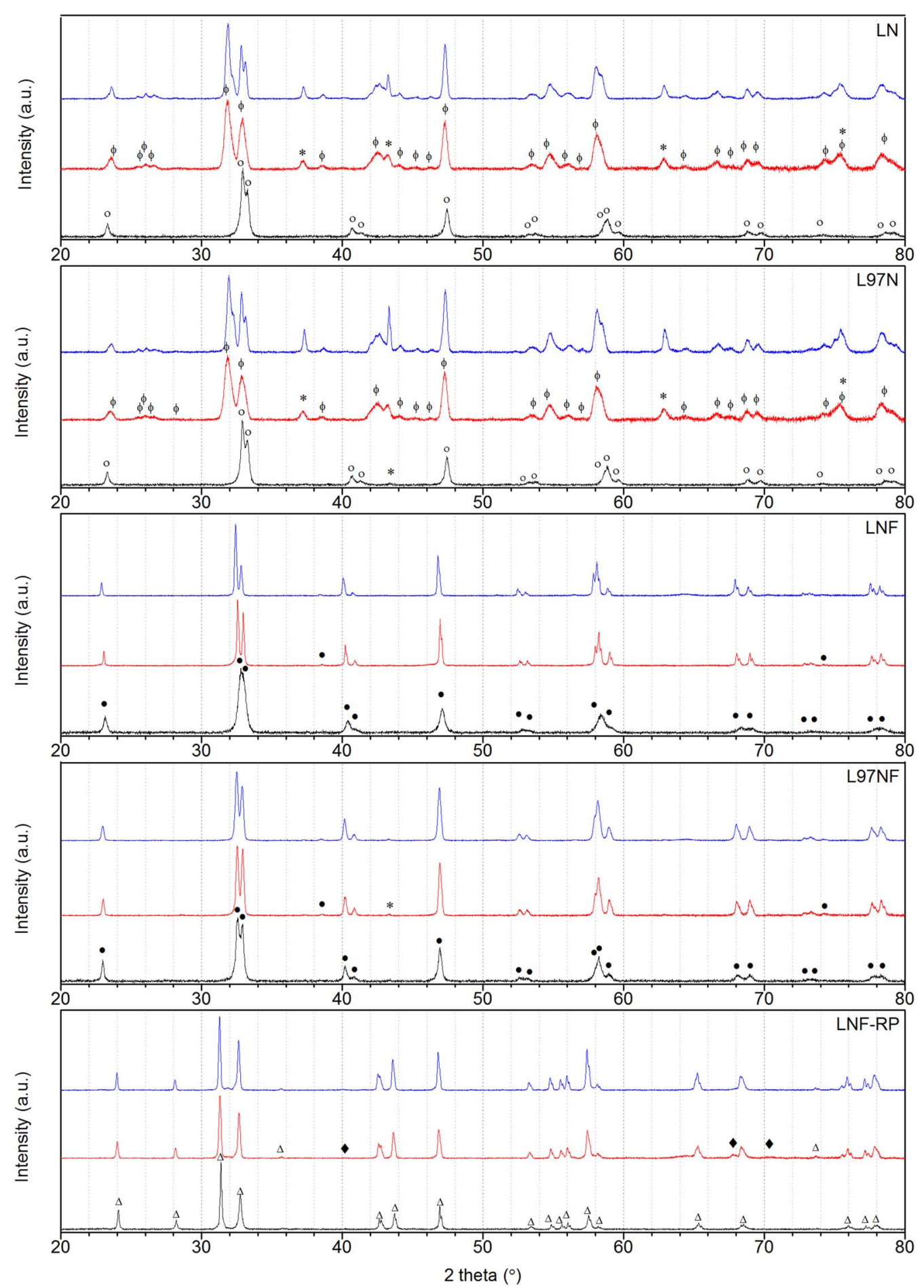

Figure 1. The XRD patterns of the as-received/calcined powder (black), the densely sintered and polished bars (red) and the electrochemically tested bars (blue). The symbols represent the following phases: $\circ \mathrm{LN},-\mathrm{LNF}, \triangle \mathrm{LNF}-\mathrm{RP}, \Phi \mathrm{Lan}_{+1} \mathrm{Ni}_{\mathrm{n}} \mathrm{O}_{3 \mathrm{n}+1}, \mathrm{n}=1,2$ or $3,{ }^{*} \mathrm{NiO}$ and $\bullet$ unidentified. Only additional peaks are indicated above in the red and blue spectra.

perovskite phase is $7.0 \mathrm{~g} \cdot \mathrm{cm}^{-3}$; hence close to that of the calcined powder. The LNF-RP is the last to sinter and has possibly not reached its maximum sintering rate at $1400^{\circ} \mathrm{C}$. This is not surprising, when taking the relatively large particle sizes into account.

Electrochemical activity toward the OER.-The electrochemical measurements were carried out in a $1 \mathrm{M} \mathrm{KOH}$ solution made form ACS reagent $\mathrm{KOH}$ and milipore water. The fact that it is only $>85 \%$ $\mathrm{KOH}$, due to $\mathrm{KOH}$ 's hydroscopic nature, is not considered problematic as the $\mathrm{pH}$ of the $1 \mathrm{M}$ was measured to 14.0. The amount of impurities in this $\mathrm{KOH}$ is important as e.g. Fe impurities as low as $<1 \mathrm{ppm}$ have been shown to have a catalytic effect on the OER of Nickel oxyhydroxides. ${ }^{23}$ In our $\mathrm{KOH}$ the level of $\mathrm{Ni}$ and $\mathrm{Fe}$ impurities is $<10 \mathrm{ppm}$ and hence it could influence the electrocatalytic activity of non-Fe containing materials. A commonly used grade of $\mathrm{KOH}$, for determination of intrinsic electrocatalytic activity toward the OER, is $99.99 \%$ trace metals basis. ${ }^{7,9}$ This grade contains $<150 \mathrm{ppm}$ trace metal ions (excluding $\mathrm{Na}$ ) compared to $100 \mathrm{ppm}$ in ACS reagent. It 


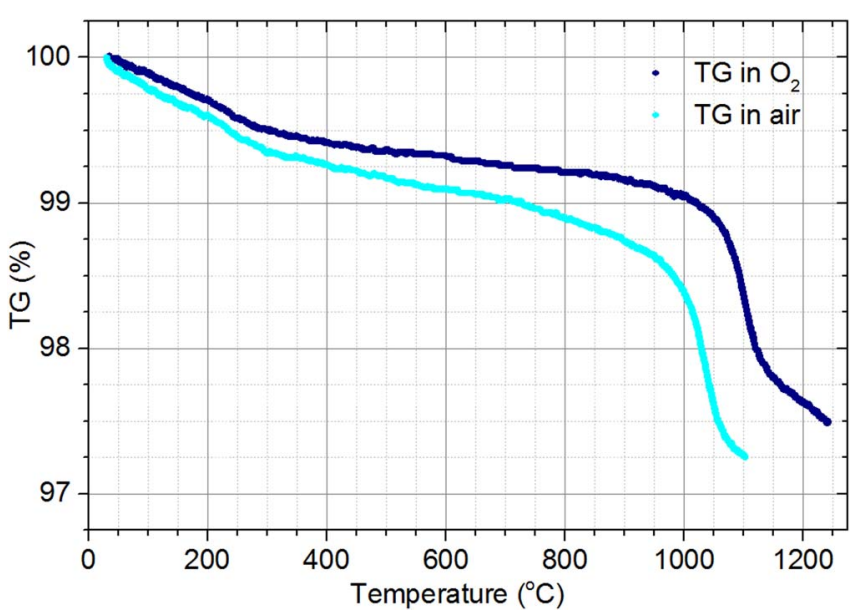

Figure 2. The TG curves of $\mathrm{LN}$ heated in air and $\mathrm{O}_{2}$. The main onset on the TG curves was determined to be $1000^{\circ} \mathrm{C}$ and $1070^{\circ} \mathrm{C}$ in air and $\mathrm{O}_{2}$ respectively.

is hence clear that the effect of impurities, such as Fe, on the OER cannot be excluded unless the highest purity grade of $\mathrm{KOH}$ (e.g. Fluka Analytical TraceSelect) is used and for all industrial applications this is not realistic.

The electrochemical characterization was carried out in two sequences, labelled test 1 and test 2 using the same sample for each test. Test 2 was carried out in a new $\mathrm{KOH}$ solution sometime after test 1. After the completion of test 2 the materials have been polarized toward the OER for a total time of 10 hours. In Figure 5a, the series of CP measurements for LNF test 2 are shown and the corresponding galvanostatic EIS measurements are presented in Figure $5 \mathrm{~b}$. The $\mathrm{CP}$ measurements at different current densities quickly reach equilibrium and remain stable, in most cases, for the 30 min duration of the measurement. The $\mathrm{CP}$ measurements are stable up to a current density

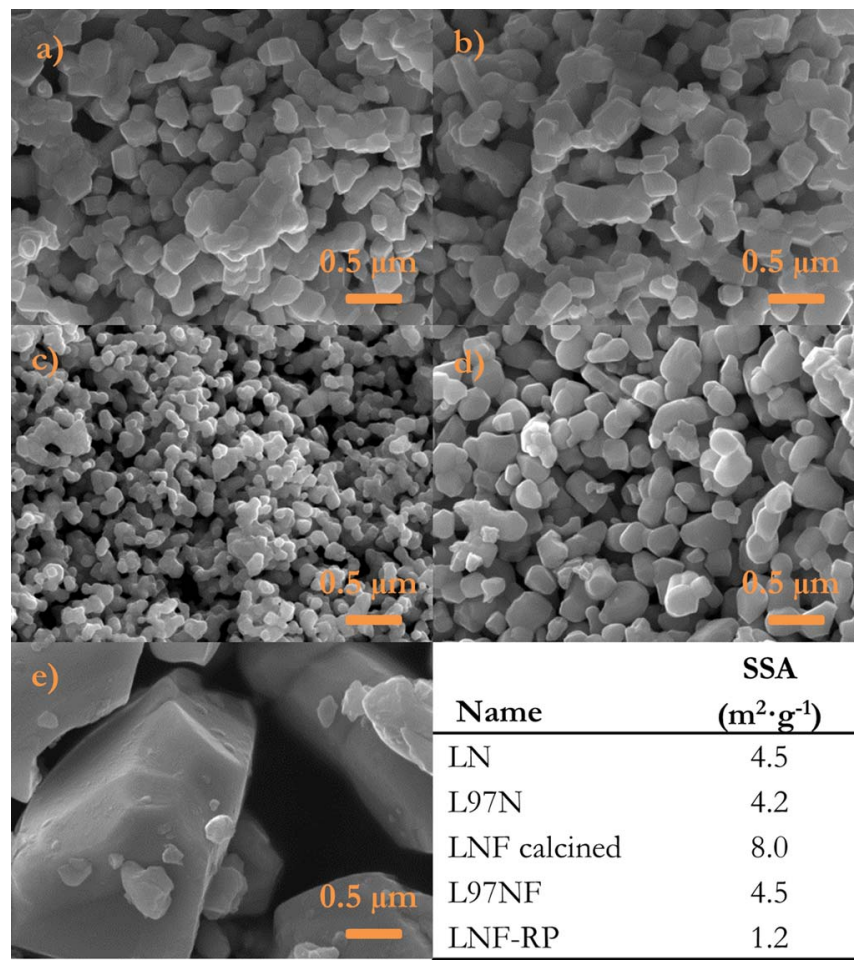

Figure 3. SEM micrographs of the powders as received from the supplier (the LNF has been calcined and is not as received) and their respective SSA. The order is as follows: a) LN, b) L97N, c) LNF, d) L97NF, e) LNF-RP.

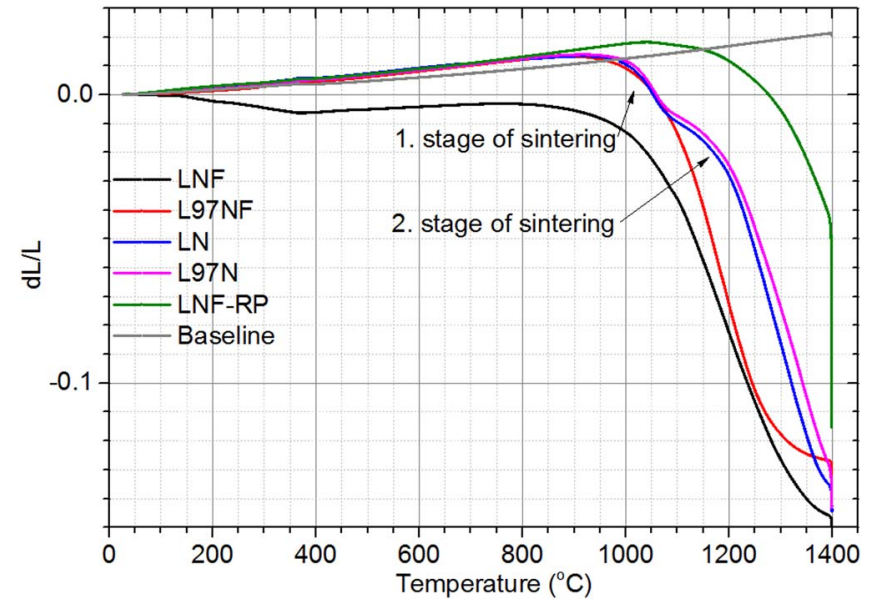

Figure 4. Sintering dilatometry curves of the pressed powders from RT to $1400^{\circ} \mathrm{C}$ in air.

of $5-10 \mathrm{~mA} \cdot \mathrm{cm}^{-2}$ above which significant fluctuations, attributed to bubble formation on the sample surface, appear. When a bubble grows on the sample surface, less surface area is available for the OER and the overpotential increases. When the bubble detaches from the surface, the overpotential decreases abruptly. For this reason, the $\mathrm{CP}$ measurements at 25 and $50 \mathrm{~mA} \cdot \mathrm{cm}^{-2}$ are not included in the data analysis. All the tested samples showed comparable serial resistance in the range of $2-4 \Omega \cdot \mathrm{cm}^{2}$.

A comparison of the OER activity of the tested materials is attempted in the Tafel plots shown in Figure 6. LN and LNF-RP exhibit the lowest overpotentials at $10 \mathrm{~mA} \cdot \mathrm{cm}^{-2}$ and the lowest Tafel slopes. The Tafel slope is obtained from the fitting of the data to the Tafel equation given by:

$$
\eta=b \ln \left(\frac{i}{i_{0}}\right)
$$

where $\eta$ is the overpotential, $b$ is the Tafel slope, $i$ is the current density and $i_{0}$ is the exchange current density. The fitting parameters $i_{0}$ and $b$ are listed in Table I together with the coefficient of determination $\left(\mathrm{R}^{2}\right)$ for each fit. It should be noted that the exchange current density, $i_{0}$, has no clear physical meaning in the OER as it is a multi-electron transfer process involving several reaction steps. ${ }^{24}$ The Tafel slope in Table I is determined in the interval $0.5-5 \mathrm{~mA} \cdot \mathrm{cm}^{-2}$. In addition all overpotentials in Table I and Figure 6 were average values of the first $5 \mathrm{~min}$ of the $\mathrm{CP}$ measurement to limit the influence of bubble formation on the overpotential.

The Tafel plots of test 1 and test 2, shown in Figure 6, suggest that the electrochemical performance increases over time. A loss of gloss on the sample surface was easily visible with the naked eye when comparing the area of the sample that was exposed to the OER conditions versus the area that was not exposed. The improved activity is attributed to an increase in the exposed surface area due to increased surface roughness. SEM micrographs of the surfaces of the bars before and after testing clearly support this observation as shown in Figure 7. In the figure the LN (a), b) and c)), LNF (d), e) and f)) and LNF-RP (g), h) and i)) surfaces are shown before and after OER testing. Trenches are formed on the surface after electrochemical testing, which is particularly visible on the LN and LNF-RP surfaces (Figures $7 \mathrm{~b}, 7 \mathrm{c}, 7 \mathrm{~h}$ and $7 \mathrm{i}$ ). The surface of the exposed LNF (Figures $7 \mathrm{e}$ and 7f) is less affected though some smaller trenches are also visible here. Reference surfaces exposed to $1 \mathrm{M} \mathrm{KOH}$ for approx. $15 \mathrm{~h}$ but not polarized toward the OER are found in Figure S1. They show that the LN and LNF surfaces are similar to the polished non-exposed surfaces. There are some small crater like features, visible in the high magnification LNF-RP surface. This is likely a result of chemical etching. The trenches formed in the surface of the electrochemically exposed samples are more pronounced, and it is therefore conjectured 

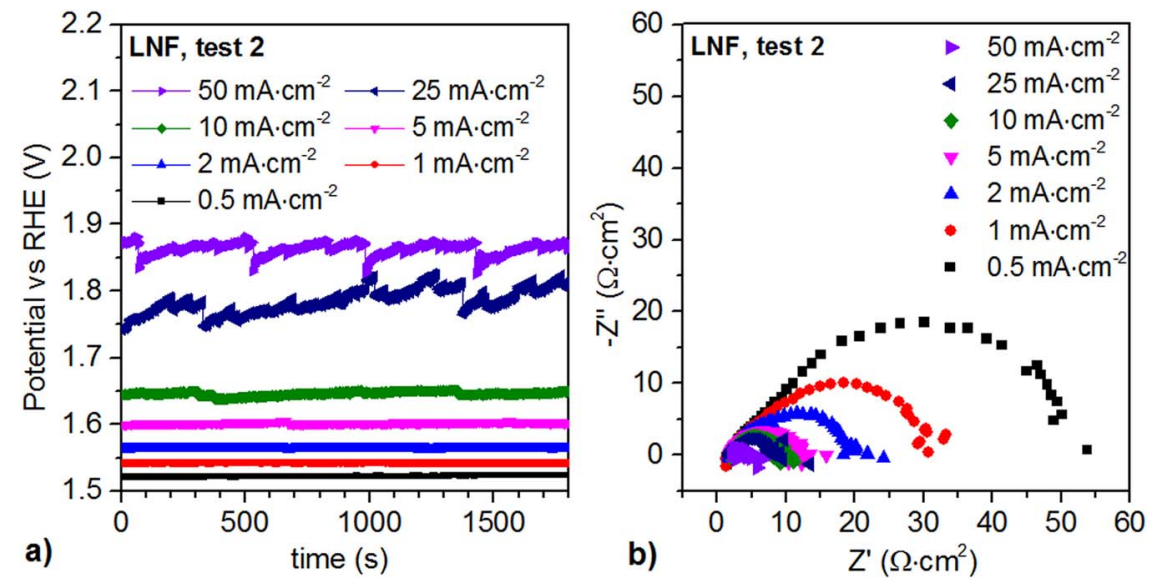

Figure 5. a) A set of $\mathrm{CP}$ measurements at different current densities for LNF and b) the corresponding amperostatic EIS measurements. The CP measurements above $10 \mathrm{~mA} \cdot \mathrm{cm}^{-2}$ are fluctuating due to bubble formation.

Table I. Tafel fit parameters for the first (test 1) and second (test 2) set of CP measurements. ${ }^{*} \mathrm{LN}$ and L97N decomposed during sintering to a multiphase material containing $\mathrm{LN}, \mathrm{NiO}$ and $\mathrm{La}_{2} \mathrm{NiO}_{4}$.

\begin{tabular}{|c|c|c|c|c|}
\hline Material & $\mathrm{b}(\mathrm{mV} / \mathrm{dec})$ & $\mathrm{i}_{0}\left(\mathrm{~mA} \cdot \mathrm{cm}^{-2}\right)$ & $\mathrm{R}^{2}$ & $\eta(\mathrm{V}) @ 10 \mathrm{~mA} \cdot \mathrm{cm}^{-2}$ \\
\hline \multicolumn{5}{|l|}{ Test 1} \\
\hline $\mathrm{LaNi}_{0.6} \mathrm{Fe}_{0.4} \mathrm{O}_{3}$ & 98 & $7 \times 10^{-4}$ & 1.00 & 0.44 \\
\hline $\mathrm{La}_{0.97} \mathrm{Ni}_{0.6} \mathrm{Fe}_{0.4} \mathrm{O}_{3}$ & 83 & $1 \times 10^{-4}$ & 0.97 & 0.45 \\
\hline $\mathrm{La}_{0.97} \mathrm{NiO}_{3}{ }^{*}$ & 78 & $4 \times 10^{-5}$ & 0.96 & 0.44 \\
\hline $\mathrm{La}_{2} \mathrm{Ni}_{0.9} \mathrm{Fe}_{0.1} \mathrm{O}_{4}$ & 66 & $2 \times 10^{-5}$ & 0.98 & 0.40 \\
\hline \multicolumn{5}{|l|}{ Test 2} \\
\hline $\mathrm{LaNiO}_{3} *$ & 56 & $2 \times 10^{-6}$ & 0.99 & 0.38 \\
\hline $\mathrm{La}_{0.97} \mathrm{NiO}_{3}{ }^{*}$ & 80 & $6 \times 10^{-5}$ & 1.00 & 0.43 \\
\hline $\mathrm{La}_{2} \mathrm{Ni}_{0.9} \mathrm{Fe}_{0.1} \mathrm{O}_{4}$ & 57 & $3 \times 10^{-5}$ & 0.97 & 0.39 \\
\hline
\end{tabular}

that these are a result of the OER. In Table II the tested bar's root mean square roughness is listed before test 1 and after test 2 . In all cases it is seen to increase but there is no clear quantitative correlation between the increase in surface roughness and the improvement in electrocatalytic activity. The mass change of the bars after vs before electrochemical testing has been recorded. For all materials there appear to be a mass loss but it is insignificant due to the uncertainty on the scale, which means the mass loss, if any, is $\leq 0.2 \mathrm{mg}(\leq 0.4 \%$ ) .

To get more insight into the activation of the electrode surfaces the ECSA has been determined as the ratio of the electrode surface

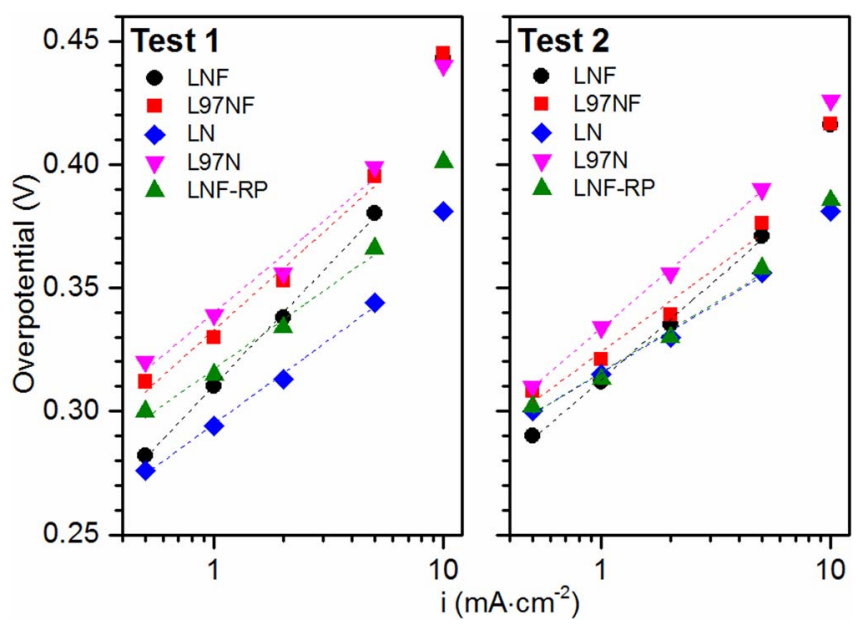

Figure 6. Tafel plots for the two sets of measurements (test 1 and test 2) of the different compositions. The dotted lines correspond to the linear fitting of the data using the Tafel equation. double layer capacitance $\left(C_{d l}\right)$ to that of an ideal oxide surface. The latter reference used is $60 \mu \mathrm{F} / \mathrm{cm}^{2}{ }^{25}$ The $C_{d l}$ is determined from chronopotentiostatic EIS fits to a resistor in series with a parallel connection of a constant phase element $(\mathrm{CPE})$ and a resistor $\left(\mathrm{R}_{\mathrm{s}}[\mathrm{CPE}-\right.$ $\left.R_{p}\right]$ ). The double layer capacitance of the electrode surface is extracted from Ref. 26:

$$
C_{d l}=Y^{1 / \alpha}\left(\frac{1}{R_{s}}+\frac{1}{R_{p}}\right)^{1-1 / \alpha}
$$

Where $\mathrm{Y}$ and $\alpha$ are the parameters describing the non-ideal capacitive behavior of the CPE. The change in ECSA at $0.5,10$ and $50 \mathrm{~mA} \cdot \mathrm{cm}^{-2}$ is compared in Table III. Firstly, it is seen that the ECSA is close to 1 (real surface area) and comparable for the different samples. Secondly, it is seen that $\mathrm{LN}$ and $\mathrm{L} 97 \mathrm{~N}$ exhibit a 3-4 fold increase in the ECSA from test 1 to test 2, which is substantially lower for the LNF, L97NF and LNF-RP. A clear correlation to the electrochemical activity measurements is not present. This is clear when comparing e.g. LN/L97N to LNF. The former exhibit a larger increase in ECSA compared to LNF, but LNF shows a larger improvement in electrocatalytic

\footnotetext{
Table II. The root mean square roughness of the polished bars' surface before electrochemical testing (pre) and after two electrochemical test cycles (post).
}

\begin{tabular}{cccc} 
Sample & $\mathrm{R}_{\mathrm{RMS}}(\mathrm{pre})[\mu \mathrm{m}]$ & $\mathrm{R}_{\mathrm{RMS}}(\mathrm{post})[\mu \mathrm{m}]$ & Increase $(\%)$ \\
\hline LN & 0.41 & 0.79 & 93 \\
L97N & 0.43 & 0.92 & 114 \\
LNF & 0.37 & 0.68 & 84 \\
L97NF & 0.37 & 0.49 & 32 \\
LNF-RP & 0.20 & 0.64 & 220
\end{tabular}




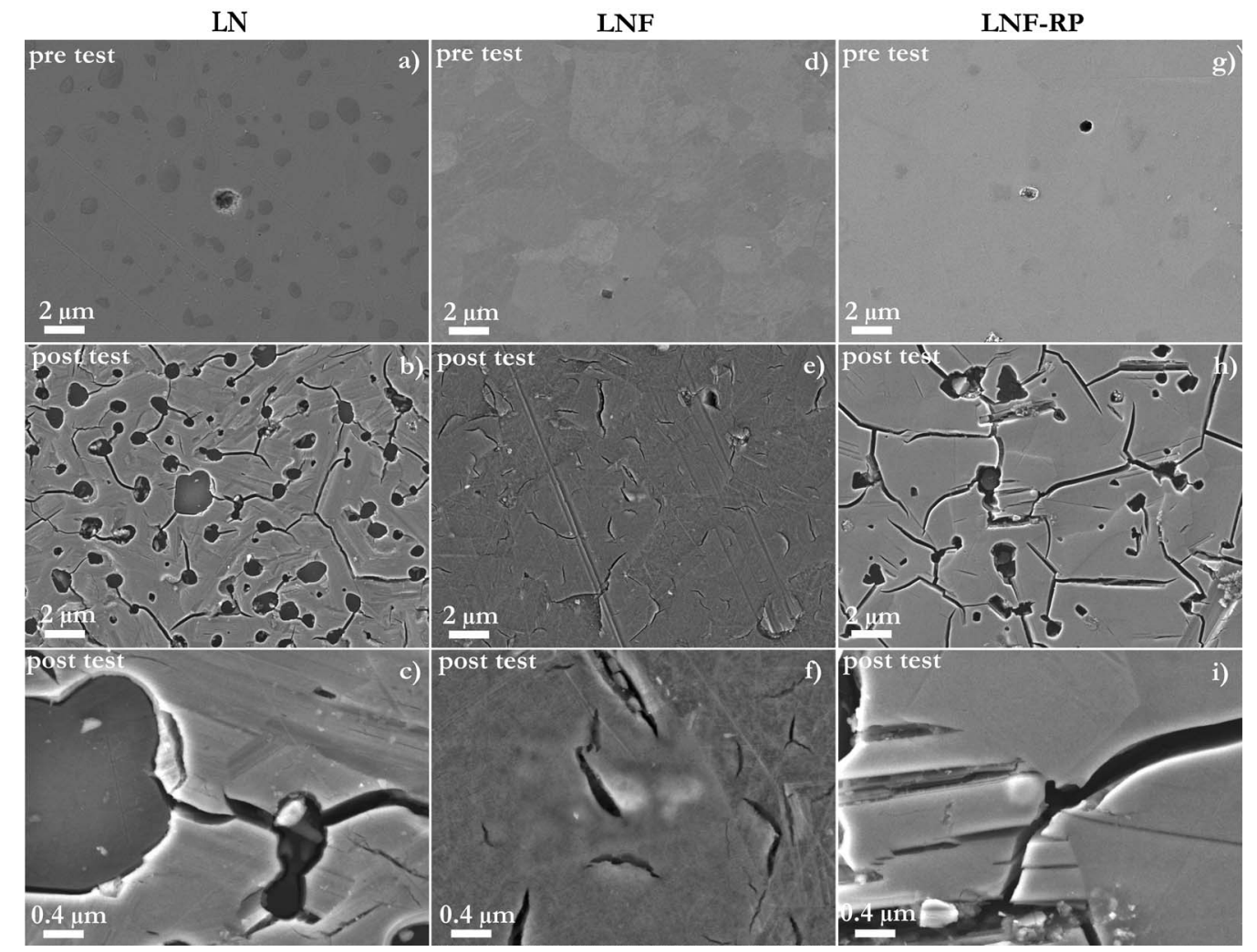

Figure 7. The surface of polished LN, LNF and LNF-RP bars before (pre test) and after (post test) the two sequences of electrochemical measurements. The darker spots in a), b) and c) is $\mathrm{NiO}$ formed during sintering.

activity. The last trend observable is a decrease in the absolute ECSA when increasing the current density. This suggests that gas bubbles are partially blocking the electrode surface and influencing the results already at $10 \mathrm{~mA} \cdot \mathrm{cm}^{-2}$.

The oxygen evolution activity of the investigated materials is compared to some of the state-of-the art materials such as $\mathrm{IrO}_{\mathrm{x}}$, $\mathrm{Ni}_{0.9} \mathrm{Fe}_{0.1} \mathrm{O}_{\mathrm{x}}$ and $\mathrm{PrBaCo}_{2} \mathrm{O}_{5+\mathrm{x}}$. in Table IV. The comparison is based on the Tafel slope and the overpotential at $10 \mathrm{~mA} \cdot \mathrm{cm}^{-2}$. Since the surface is seen to change over time, results from the first set of measurements (test1) are chosen as more representative of the intrinsic activity of the materials. The activity of LN varies substantially when looking into the literature; the Tafel slopes reported vary from $43-122 \mathrm{mV},{ }^{6,28-31}$ in $0.1 / 1.0 \mathrm{M} \mathrm{KOH}$. The variation is likely a result of several factors. Firstly, that different (ratio of) components are used in the electrocatalyst layer e.g. different types of carbon, nafion and PTFE used to collect current and support the catalyst particles. Secondly, that the synthesis method influences the intrinsic OER activity. ${ }^{27}$ This is related to changes in the actual crystal structure and phase composition. In Ref. 28 it was for example shown that the change of crystal structure from rhombohedral to cubic LN perovskite has an enhancing effect on the OER activity. Lastly, surface roughening and instability of the surface perovskite phase is likely a third factor influencing the results. In Ref. 30 the intrinsic OER activity of $\mathrm{LN}$ and $\mathrm{La}_{\mathrm{n}+\mathbf{1}} \mathrm{Ni}_{\mathrm{n}} \mathrm{O}_{3 \mathrm{n}+1}(\mathrm{n}=1,2$ and 3) was investigated and the lowest Tafel slope was found for $\mathrm{LN}(122 \mathrm{mV} / \mathrm{dec})$, followed by $\mathrm{La}_{4} \mathrm{Ni}_{3} \mathrm{O}_{10.26}(142 \mathrm{mV} / \mathrm{dec}) \mathrm{La}_{2} \mathrm{NiO}_{4.27}(180 \mathrm{mV} / \mathrm{dec})$ and $\mathrm{La}_{3} \mathrm{Ni}_{2} \mathrm{O}_{7.15}$ $(250 \mathrm{mV} / \mathrm{dec})$. Finally, the OER activity of $\mathrm{NiO}$ has generally been reported for the related $\mathrm{Ni}(\mathrm{OH})_{2}$ and $\mathrm{NiO}(\mathrm{OH})$ species as these can be formed as a surface layer in alkaline conditions ${ }^{32}$ and known to be the electrocatalytically active phases. Tafel slopes reported are generally low, on the order of 30-40 mV/dec ${ }^{33-35}$ though higher values have also been reported $(70 / 100 \mathrm{mV} / \mathrm{dec})^{15,36}$ when no Fe impurities are present. The other materials, investigated in this article have, to our knowledge, not been investigated toward the OER in alkaline media previously.

Chemical stability of the materials at high temperatures in concentrated $\mathrm{KOH}$.- The XRD patterns of LN, LNF, and LNF-RP powders after 1 week of ageing under conditions similar to actual HTPAECs operating conditions $\left(45 \mathrm{wt} \% \mathrm{KOH}\right.$ at $220^{\circ} \mathrm{C}$ but no electrochemistry involded) are shown in Figure 8. The results show that all

\section{Table III. The electrochemical active surface area (ECSA) of the tested bars at different current densities.}

\begin{tabular}{|c|c|c|c|c|c|c|c|c|c|}
\hline \multirow[b]{2}{*}{ Sample } & $\begin{array}{c}\text { ECSA } \\
\text { test } 1\end{array}$ & $\begin{array}{c}\text { ECSA } \\
\text { test } 2\end{array}$ & $\begin{array}{c}\text { Change } \\
(\%)\end{array}$ & $\begin{array}{c}\text { ECSA } \\
\text { test } 1\end{array}$ & $\begin{array}{c}\text { ECSA } \\
\text { test } 2\end{array}$ & $\begin{array}{c}\text { Change } \\
(\%)\end{array}$ & $\begin{array}{c}\text { ECSA } \\
\text { test } 1\end{array}$ & $\begin{array}{c}\text { ECSA } \\
\text { test } 2\end{array}$ & $\begin{array}{c}\text { Change } \\
(\%)\end{array}$ \\
\hline & \multicolumn{3}{|c|}{$0.5 \mathrm{~mA} \cdot \mathrm{cm}^{-2}$} & \multicolumn{3}{|c|}{$10 \mathrm{~mA} \cdot \mathrm{cm}^{-2}$} & \multicolumn{3}{|c|}{$50 \mathrm{~mA} \cdot \mathrm{cm}^{-2}$} \\
\hline LN & 2.5 & 12.3 & $390 \%$ & 1.3 & 5.7 & $334 \%$ & 0.8 & N/A & - \\
\hline L97N & 2.7 & 12.2 & $351 \%$ & 1.4 & 3.8 & $167 \%$ & 1.3 & 0.9 & $-34 \%$ \\
\hline LNF & 4.7 & 5.4 & $14 \%$ & 1.9 & 2.5 & $33 \%$ & 0.8 & 1.0 & $24 \%$ \\
\hline L97NF & 3.0 & 7.3 & $142 \%$ & 1.8 & 3.6 & $102 \%$ & 0.7 & 0.8 & $10 \%$ \\
\hline $\begin{array}{l}\text { LNF- } \\
\text { RP }\end{array}$ & 2.0 & 4.5 & $123 \%$ & 0.7 & 0.7 & $0 \%$ & 0.5 & 0.4 & $-9 \%$ \\
\hline
\end{tabular}


Table IV. Figures of merit for various perovskites and metal oxides from the literature. $\mathrm{IrO}_{\mathrm{x}}$ and $\mathrm{NiFeO}_{\mathrm{x}}$ are state-of-the-art $\mathrm{OER}$ catalysts. $\mathrm{PrBaCo}_{2} \mathrm{O}_{5+\mathrm{x}}$ is one of the best performing perovskites (double perovskite), which also shows stable performance at standard conditions.

\begin{tabular}{|c|c|c|c|}
\hline Material & $\mathrm{b}(\mathrm{mV} / \mathrm{dec})$ & $\eta(\mathrm{V}) @ 10 \mathrm{~mA} \cdot \mathrm{cm}^{-2}$ & Conditions \\
\hline $\mathrm{IrO}_{\mathrm{x}}{ }^{33}$ & 49 & $\mathrm{n} / \mathrm{a}$ & $1 \mathrm{M} \mathrm{KOH}, \mathrm{RT}$, geometric surface area \\
\hline $\mathrm{IrO}_{\mathrm{x}}^{36}$ & $\mathrm{n} / \mathrm{a}$ & 0.32 & $1 \mathrm{M} \mathrm{KOH}, \mathrm{RT}$, geometric surface area \\
\hline $\mathrm{Ni}_{0.9}{ }^{\mathrm{A}} \mathrm{Fe}_{0.1} \mathrm{O}_{\mathrm{x}}{ }^{33}$ & 30 & $\mathrm{n} / \mathrm{a}$ & $1 \mathrm{M} \mathrm{KOH}, \mathrm{RT}$, geometric surface area \\
\hline $\mathrm{PrBaCO}_{2} \mathrm{O}_{5+\mathrm{x}}{ }^{8}$ & $\sim 70$ & $\sim 0.38$ & $0.1 \mathrm{M} \mathrm{KOH}, \mathrm{RT}$, oxide surface area \\
\hline $\mathrm{PrBaCO}_{2} \mathrm{O}_{5+\mathrm{x}}{ }^{37}$ & $\sim 95$ & $\mathrm{n} / \mathrm{a}$ & $0.1 \mathrm{M} \mathrm{KOH}, \mathrm{RT}$, mass based normalization \\
\hline
\end{tabular}
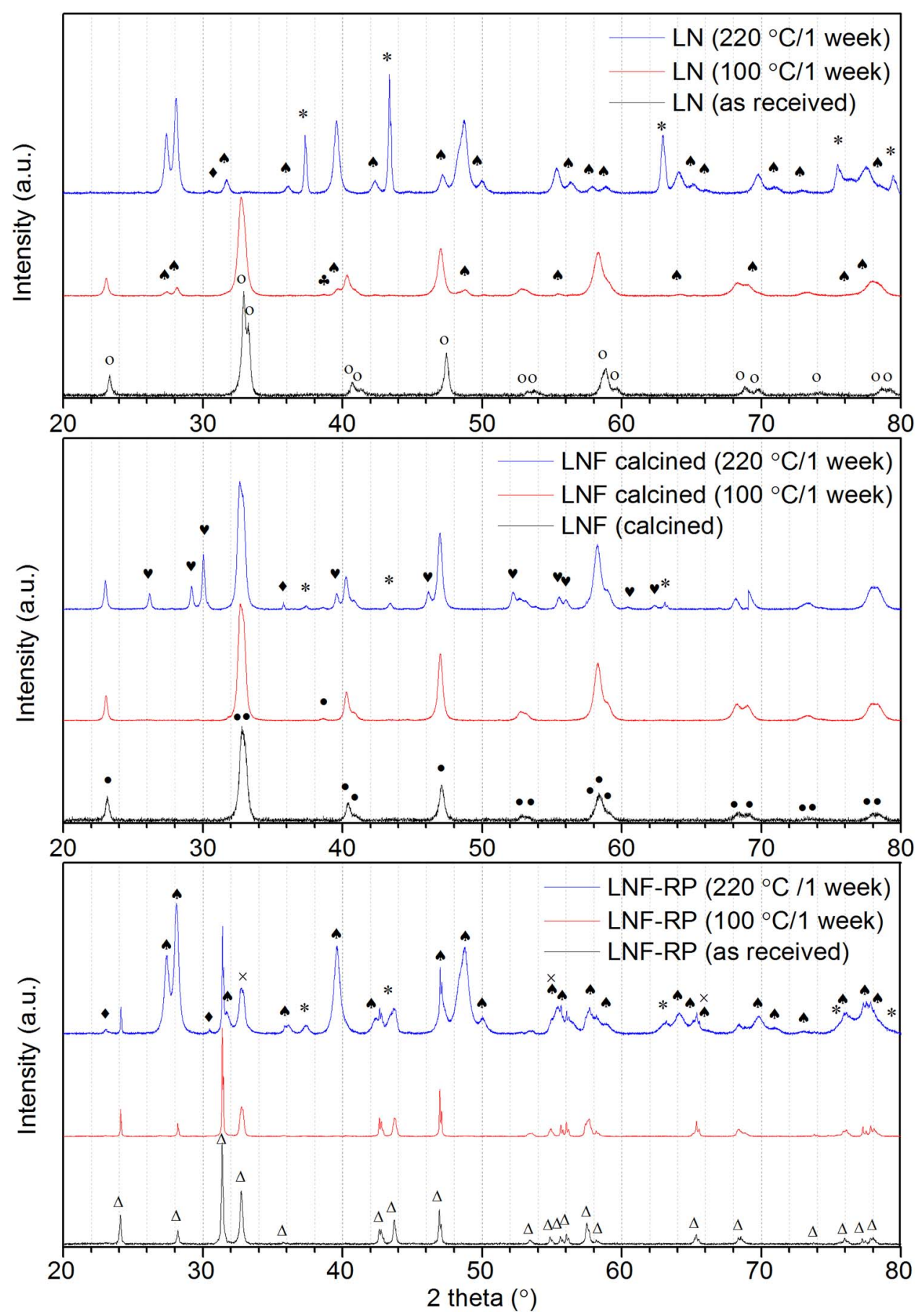

Figure 8. The XRD pattern of the LN, LNF and LNF-RP powder and the same powder after 1 weeks exposure to $31 \mathrm{wt} \% \mathrm{KOH}$ at $100^{\circ} \mathrm{C}$ and $45 \mathrm{wt} \% \mathrm{KOH}$ at

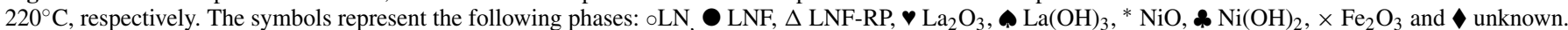
Only additional peaks are indicated in the red and blue spectrum. 
materials have decomposed. The peaks corresponding to the decomposition products are indexed to $\mathrm{La}(\mathrm{OH})_{3}$ (PDF 36-1481) and $\mathrm{NiO}$ (PDF-44-1159) in the case of $\mathrm{LN}$ and $\mathrm{La}(\mathrm{OH})_{3}, \mathrm{NiO}$ and $\mathrm{Fe}_{2} \mathrm{O}_{3}$ (PDF 39-0238) in the case of LNF and LNF-RP. A few minor peaks in the XRD patterns remained unidentified. The perovskite phase is almost completely decomposed to $\mathrm{La}(\mathrm{OH})_{3}$ and $\mathrm{NiO}$ in the $\mathrm{LN}$ powder. In the LNF-RP powder the $\mathrm{La}(\mathrm{OH})_{3}$ peaks dominate while the perovskite phase is still the main phase in the LNF powder. The XRD patterns of the powders after exposure to less harsh conditions (31 wt \% $\mathrm{KOH}$ at $100^{\circ} \mathrm{C}$ ) are also found in Figure 8 . The $\mathrm{LN}$ perovskite phase shows some decomposition but significantly less than after the $220^{\circ} \mathrm{C}$ test. The LNF and LNF-RP powder exhibit very limited degradation after the $100^{\circ} \mathrm{C}$ test. At higher magnification it appears that small traces of $\mathrm{LaO}(\mathrm{OH})$ (PDF 19-0656), $\mathrm{La}(\mathrm{OH})_{3}$ and $\mathrm{NiO}$ are present. A longer stability test is necessary though to reach a clear conclusion on whether the apparently improved stability at $100^{\circ} \mathrm{C}$ vs $220^{\circ} \mathrm{C}$ is associated with slow kinetics for the decomposition process or improved thermodynamic stability of the perovskite phases explored. The chemical stability test of the powders exposed to concentrated $\mathrm{KOH}$ for a week at RT, show signs of secondary phases in the LN XRD spectrum and no signs in the LNF and LNF-RP XRD spectra (see Figure S2).

Apart from the LNF and L97NF, the other porously sintered pellets exposed to the $220^{\circ} \mathrm{C}$ chemical stability test had crumbled into powder. All the porous pellets exposed to the $100^{\circ} \mathrm{C}$ test remained intact. The XRD patterns of the LNF and LNF-RP pellets exposed to the $100^{\circ} \mathrm{C}$ test showed a similar pattern as the powders exposed to the same conditions. The LN pellets were already partially decomposed during sintering to $\mathrm{NiO}$ and Ruddlesden-Popper phases. Clear signs of $\mathrm{La}(\mathrm{OH})_{3}$ were present in the XRD of the tested pellets, thus indicating that the sintered mixed phase material is not chemically stable. It cannot be concluded whether the new phases formed are only the $\mathrm{LaNiO}_{3}$ decomposing further or also a result of the Ruddlesden-Popper phases, formed during sintering, decomposing.

\section{Conclusions}

$\mathrm{La}, \mathrm{Ni}$ (and $\mathrm{Fe}$ ) based perovskites and a Ruddlesden-Popper compound were investigated as electrode materials for the OER in alkaline medium. The intrinsic electrochemical activity was determined at room temperature in $1 \mathrm{M} \mathrm{KOH}$ and found to be comparable for all materials, with the multiphase- $\mathrm{LN}\left(\mathrm{LN}, \mathrm{La}_{\mathrm{n}+1} \mathrm{Ni}_{\mathrm{n}} \mathrm{O}_{3 \mathrm{n}+1}, \mathrm{NiO}\right)$ and the LNF-RP exhibiting the highest activity. The Tafel slopes were in the range $56-98 \mathrm{mV} / \mathrm{dec}$. and the overpotential at $10 \mathrm{~mA} \mathrm{~cm}{ }^{-2}$ in the range $0.38-0.45 \mathrm{~V}$, which is similar to that of state-of-art, nonnoble metal electrocatalysts. The roughness of the polished surface of all materials was increasing over time, accounting for the increase in electrochemical activity observed over time. The decrease in the ECSA, observed at higher current densities $\left(50 \mathrm{~mA} \cdot \mathrm{cm}^{-2}\right)$, is probably due to the formation of gas bubbles on the electrode surface.

Chemical stability measurements of the powders exposed to $31 \mathrm{wt} \%$ and $45 \mathrm{wt} \% \mathrm{KOH}$ respectively at $100^{\circ} \mathrm{C}$ and $220^{\circ} \mathrm{C}$ for 1 week showed that all the studied materials were chemically unstable at $220^{\circ} \mathrm{C}$, decomposing to simple metal oxides and hydroxides. At $100^{\circ} \mathrm{C}$ the LNF and LNF-RP powders showed only traces of secondary phases, whereas the LN powder is clearly decomposing. These materials are therefore not appropriate for HTP-AECs but LNF and LNF-RP could potentially be used at temperatures below $100^{\circ} \mathrm{C}$. Further stability investigations of even longer duration are required to assess this.

\section{Acknowledgments}

The authors thank Jette Iversen, Jeanette Krambech and Carsten G. Sørensen for their help with sample preparation and carrying out measurements. We are also grateful for the help Jens F. S. Borchsenius, Henrik Henriksen and Jens Østergaard provided in conjunction with the electrochemical characterization.

\section{ORCID}

Jens Q Adolphsen (iD https://orcid.org/0000-0001-5062-0118

\section{References}

1. T. Smolinka, E. T. Ojong, and J. Garche, in Electrochemical Energy Storage for Renewable Sources and Grid Balancing, P. T. Moseley and J. Garche, Editors, p. 103, Elsevier (2014).

2. K. Zeng and D. Zhang, "Recent progress in alkaline water electrolysis for hydrogen production and applications," Prog. Energy Combust. Sci., 36(3), 307 (2010).

3. F. Allebrod, C. Chatzichristodoulou, and M. B. Mogensen, "Alkaline electrolysis cell at high temperature and pressure of $250^{\circ} \mathrm{C}$ and 42 bar," J. Power Sources, 229, 22 (2013).

4. F. Allebrod, C. Chatzichristodoulou, and M. B. Mogensen, "Cobalt and molybdenum activated electrodes in foam based alkaline electrolysis cells at 150-250 C and 40 bar," J. Power Sources, 255, 394 (2014).

5. C. Chatzichristodoulou, F. Allebrod, and M. B. Mogensen, "High Temperature Alkaline Electrolysis Cells with Metal Foam Based Gas Diffusion Electrodes," J. Electrochem. Soc., 163(11), 3036 (2016).

6. J. O. Bockris and T. Otagawa, "The Electrocatalysis of Oxygen Evolution on Perovskites," J. Electrochem. Soc., 131(2), 290 (1984).

7. J. Suntivich, K. J. May, H. A. Gasteiger, J. B. Goodenough, and Y. Shao-Horn, “A Perovskite Oxide Optimized for Oxygen Evolution Catalysis from Molecular Orbital Principles," Science, 334, 1383 (2011).

8. A. Grimaud, K. J. May, C. E. Carlton, Y.-L. Lee, M. Risch, W. T. Hong, J. Zhou, and Y. Shao-Horn, "Double perovskites as a family of highly active catalysts for oxygen evolution in alkaline solution.", Nat. Commun., 4, 2439 (2013).

9. R. Mohamed, X. Cheng, E. Fabbri, P. Levecque, R. Kotz, O. Conrad, and T. J. Schmidt, "Electrocatalysis of Perovskites: The Influence of Carbon on the Oxygen Evolution Activity," J. Electrochem. Soc., 162(6), F579 (2015).

10. D. S. Bick, A. Kindsmüller, G. Staikov, F. Gunkel, D. Müller, T. Schneller, R. Waser, and I. Valov, "Stability and Degradation of Perovskite Electrocatalysts for Oxygen Evolution Reaction," Electrochim. Acta, 218, 156 (2016).

11. D. Bick, T. B. Krebs, D. Kleimaier, A. F. Zurhelle, G. T. Staikov, R. Waser, and I. Valov, "Degradation Kinetics during Oxygen Electrocatalysis on Perovskite-based Surfaces in Alkaline Media," Langmuir, 34, 1347 (2018).

12. S. Trasatti, "Electrocatalysis in the anodic evolution of oxygen and chlorine," Electrochim. Acta, 29(11), 1503 (1984).

13. Y. Matsumoto and E. Sato, "Electrocatalytic properties of transition metal oxides for oxygen evolution reaction," Mater. Chem. Phys., 14(5), 397 (1986).

14. Y. Lee, J. Suntivich, K. J. May, E. E. Perry, and Y. Shao-Horn, "Synthesis and Activities of Rutile $\mathrm{IrO}_{2}$ and $\mathrm{RuO}_{2}$ Nanoparticles for Oxygen Evolution in Acid and Alkaline Solutions," J. Phys. Chem. Lett., 3, 399 (2012).

15. D. A. Corrigan, "The Catalysis of the Oxygen Evolution Reaction by Iron Impurities in Thin Film Nickel Oxide Electrodes," J. Electrochem. Soc., 134(2), 377 (1987).

16. M. D. Merrill and R. C. Dougherty, "Metal oxide catalysts for the evolution of $\mathrm{O}_{2}$ from $\mathrm{H}_{2} \mathrm{O}$," J. Phys. Chem. C, 112(10), 3655 (2008).

17. D. Zhang, Y. Song, Z. Du, L. Wang, Y. Li, and J. B. Goodenough, "Active $\mathrm{LaNi}_{1-\mathrm{x}} \mathrm{Fe}_{\mathrm{x}} \mathrm{O}_{3}$ bifunctional catalysts for air cathodes in alkaline media," J. Mater. Chem. A, 3(18), 9421 (2015).

18. E. V. Tsipis, E. N. Naumovich, M. V. Patrakeev, J. C. Waerenborgh, Y. V. Pivak, P. Gaczyński, and V. V. Kharton, "Oxygen non-stoichiometry and defect thermodynamics in $\mathrm{La}_{2} \mathrm{Ni}_{0.9} \mathrm{Fe}_{0.1} \mathrm{O}_{4+\mathrm{d}}$," J. Phys. Chem. Solids, 68, 1443 (2007).

19. C. Brisi, M. Vallino, and F. Abbattista, "Composition and structure of two hitherto unidentified phases in the system $\mathrm{La}_{2} \mathrm{O}_{3}$-NiO-O," J. Less-Common Met., 79(2), 215 (1981).

20. J. Drennan, C. P. Tavares, and B. C. H. Steele, "An Electron Microscope Investigation of Phases in the System La-Ni-O," Mater. Res. Bull., 17, 621 (1982).

21. H. E. Höfer and W. F. Kock, "Crystal Chemistry and Thermal Behavior in the $\mathrm{La}(\mathrm{Cr}, \mathrm{Ni}) \mathrm{O}_{3}$ Perovskite System," J. Electrochem. Soc., 140(10), 2889 (1993).

22. M. Zinkevich, N. Solak, H. Nitsche, M. Ahrens, and F. Aldinger, "Stability and thermodynamic functions of lanthanum nickelates," J. Alloys Compd., 438, 92 (2007).

23. L. Trotochaud, S. L. Young, J. K. Ranney, and S. W. Boettcher, "Nickel-Iron oxyhydroxide oxygen-evolution electrocatalysts: The role of intentional and incidental iron incorporation" J. Am. Chem. Soc., 136(18), 6744 (2014).

24. W. T. Hong, M. Risch, K. A. Stoerzinger, A. Grimaud, Jin Suntivich, and Y. Shao-Horn, "Toward the rational design of non-precious transition metal oxides for oxygen electrocatalysis," Energy Environ. Sci., 8, 1404 (2015).

25. S. Levine and A. L. Smith, "Theory of the differential capacity of the oxide/aqueous electrolyte interface," Discuss. Faraday Soc., 52, 290 (1971)

26. G. J. Brug, A. L. G. Van Den Eeden, M. Sluyters-Rehbach, and J. H. Sluyters, "The Analysis of Electrode Impedances Complicated by the Presence of Constant Phase Element," J. Electroanal. Chem., 176, 275 (1984).

27. R. N. Singh, S. K. Tiwari, S. P. Singh, A. N. Jain, and N. K. Singh, "Electrocatalytic activity of high specific surface area perovskite-type $\mathrm{LaNiO}_{3}$ via sol-gel route for electrolytic oxygen evolution in alkaline solution," Int. J. Hydrogen Energy, 22(6), 557 (1997).

28. W. Zhou and J. Sunarso, "Enhancing Bi-functional electrocatalytic activity of perovskite by temperature shock: A case study of $\mathrm{LaNiO}_{3-\mathrm{d}}$," J. Phys. Chem. Lett., 4(17), 2982 (2013)

29. R. A. Silva, C. O. Soares, M. D. Carvalho, C. M. Rangel, and M. I. Da Silva Pereira, "Stability of $\mathrm{LaNiO}_{3}$ gas diffusion oxygen electrodes," J. Solid State Electrochem., 18(3), 821 (2014). 
30. J. Yu, J. Sunarso, Y. Zhu, X. Xu, R. Ran, W. Zhou, and Z. Shao, "Activity and Stability of Ruddlesden-Popper-Type $\mathrm{La}_{n+1} \mathrm{NinO}_{3 \mathrm{n}+1}(\mathrm{n}=1,2,3$, and $\infty)$ Electrocatalysts for Oxygen Reduction and Evolution Reactions in Alkaline Media," Chem. Eur. J., 22, 2719 (2016).

31. A. Ashok, A. Kumar, R. R. Bhosale, F. Almomani, S. S. Malik, S. Suslov, and F. Tarlochan, "Combustion synthesis of bifunctional $\mathrm{LaMO}_{3}(\mathrm{M}=\mathrm{Cr}, \mathrm{Mn}, \mathrm{Fe}$, $\mathrm{Co}, \mathrm{Ni})$ perovskites for oxygen reduction and oxygen evolution reaction in alkaline media," J. Electroanal. Chem., 809, 22 (2018).

32. Y. Miao, L. Ouyang, S. Zhou, L. Xu, Z. Yang, M. Xiao, and R. Ouyang, "Electrocatalysis and electroanalysis of nickel, its oxides, hydroxides and oxyhydroxides toward small molecules," Biosens. Bioelectron., 53,428 (2014).

33. L. Trotochaud, J. K. Ranney, K. N. Williams, and S. W. Boettcher, "Solution-Cast Metal Oxide Thin Film Electrocatalysts for Oxygen Evolution," J. Am. Chem. Soc., 134, 17253 (2012).
34. Y. Qiu, L. Xin, and W. Li, "Electrocatalytic oxygen evolution over supported small amorphous Ni-Fe nanoparticles in alkaline electrolyte," Langmuir, 30(26), 7893 (2014).

35. M. S. Burke, S. Zou, L. J. Enman, J. E. Kellon, C. A. Gabor, E. Pledger, and S. W. Boettcher, "Revised Oxygen Evolution Reaction Activity Trends for FirstRow Transition-Metal (Oxy)hydroxides in Alkaline Media," J. Phys. Chem. Lett., 6 3737 (2015).

36. C. C. L. McCrory, S. Jung, J. C. Peters, and T. F. Jaramillo, "Benchmarking Heterogeneous Electrocatalysts for the Oxygen Evolution Reaction," J. Am. Chem. Soc., 135, 16977 (2013)

37. R. Mohamed, X. Cheng, E. Fabbri, P. Levecque, R. Kotz, O. Conrad, and T. J. Schmidt, "Electrocatalysis of Perovskites: The Influence of Carbon on the Oxygen Evolution Activity," J. Electrochem. Soc., 162(6), F579 (2015). 